\title{
Novos fundentes para produção da porcelana de ossos
}

\author{
(New fluxes for the production of bone china) \\ M.P. Ballvé, S. R. Bragança \\ Departamento de Materiais da Universidade Federal do Rio Grande do Sul - DEMAT/UFRGS \\ Av. Osvaldo Aranha 99, 705c, Porto Alegre, RS 90035-190 \\ saulorb@ufrgs.br
}

\begin{abstract}
Resumo
O uso de fundentes enérgicos "alternativos" foi investigado em uma formulação de porcelana de ossos em ciclo de queima rápida. As propriedades dos corpos-de-prova foram avaliadas em diferentes formulações, variando-se o tipo de fundente. A wolastonita, o espodumênio e o pó de vidro foram empregados, substituindo-se parcialmente um feldspato potássico. Os resultados da caracterização tecnológica, formações de fases e microestrutura foram comparados em diferentes temperaturas. Os fundentes utilizados propiciaram uma redução na temperatura final de queima e ao mesmo tempo um amplo intervalo de gresificação. Os resultados da caracterização tecnológica das peças, após a queima das formulações propostas, mostraram que as propriedades técnicas são compatíveis com os produtos porcelânicos almejados.
\end{abstract}

Palavras-chave: porcelana de ossos, novos fundentes, queima, caracterização tecnológica.

\section{Abstract}

Strong fluxes were investigated in a bone china composition by applying a fast firing cycle. The technical properties of the ceramic bodies were evaluated. The conventional flux (potash feldspar) was partially replaced by strong fluxes (wollastonite or spodumene or waste glass). A comparative analysis of the data, including technical properties, microstructure, and phase's development at different firing temperature was performed. Due to the utilization of these strong fluxes, a reduction of firing temperature and, simultaneously, a broad firing range was achieved. Then, the main technical aspects concerning the firing of these new compositions were investigated. The final properties of the pieces were considered good for the production of bone china.

Keywords: bone china, new fluxes, firing, technological characterization.

\section{INTRODUÇÃO}

A porcelana de ossos é conhecida por sua alta qualidade técnica e características únicas de seu design, destacandose as propriedades estéticas, tais como elevado índice de alvura, brilho e translucidez, tal que as peças produzidas apresentam rara beleza [1]. O setor de louças de qualidade refinada, no entanto, praticamente inexiste no Brasil, cujos produtos competem num nicho inferior de mercado. Um aspecto bastante relevante é o fato de se produzir essa porcelana com $50 \%$ de matéria-prima proveniente de um material reciclado, como os ossos bovinos calcinados. Por conseguinte, em decorrência da recente conscientização da preservação ambiental, a porcelana de ossos passou a ter novo interesse, o que deve impulsionar ainda mais o seu desenvolvimento e consumo. Este fato levou os autores a investigar os principais parâmetros técnicos para a produção dessa porcelana, cujos resultados foram publicados em outros trabalhos [2-4]. A porcelana de ossos é produzida com 50\% de cinza de ossos, $25 \%$ de caulim e $25 \%$ feldspato. Algumas vezes, tem-se a adição de pequenas quantidades de outras matérias-primas, como quartzo ou argilas plásticas, para o aumento da resistência piroplástica e aumento da plasticidade da massa, respectivamente. Na composição dessa porcelana, o feldspato atua como fundente, reduzindo a temperatura de sinterização, sendo decisiva a sua influência sobre as propriedades técnicas finais e a estética das peças. A reação do feldspato com as cinzas de ossos e o caulim durante a queima, e alguma reação com o quartzo, quando presente, forma a fase vítrea. Esta pode chegar a 30\% do volume total do material, envolvendo as partículas mais refratárias, como o fosfato tricálcico e a anortita [5].

A formação da fase vítrea determina a temperatura e o intervalo de queima de uma cerâmica tradicional, como porcelanas, louças e revestimentos. Portanto, o controle dessa fase é a chave para a redução de temperatura de queima no processamento, o que significa uma redução direta no custo associado aos combustíveis. Consciente deste aspecto, sempre que possível, a indústria opta pela utilização de fundentes enérgicos. No entanto, no caso específico da porcelana de ossos, fundentes enérgicos são de difícil utilização, devido ao curto intervalo de queima, limitado pela baixa estabilidade térmica das peças [6].

Em uma porcelana de ossos tradicional, a composição global se situa na região do eutético de $11 \%$ fosfato tricálcico, $38 \%$ sílica e $51 \%$ anortita, com uma temperatura de fusão de $1290 \pm 5^{\circ} \mathrm{C}$. Se a queima procede lentamente, em temperaturas pouco acima de $1250{ }^{\circ} \mathrm{C}$ ocorre a deformação 
das peças [7]. Portanto, a queima deve ser realizada sem se atingir o equilíbrio, formando as conhecidas fases finais desta porcelana que são a anortita, o fosfato tricálcico e um vidro silicoso. Na queima rápida, a composição da fase vítrea muda conforme a região analisada $[7,8]$. Nestes trabalhos, a análise da composição química da fase vítrea feita por EDS mostrou teores de $\mathrm{Si}, \mathrm{Al}, \mathrm{Ca}$ e $\mathrm{Na}$ bem variados, tanto para áreas distintas dentro da microestrutura, quanto para pontos dentro de uma mesma região. Por exemplo, para pontos localizados entre cristais de fosfato tricálcico e de anortita, o teor de $\mathrm{CaO}$ variou entre 30 e $50 \%$ em análise em SEM/ EDS.

O fato de não se atingir o equilíbrio da composição da fase vítrea durante a queima deixa ainda mais complexa a previsão da condição experimental ideal de queima. Daí a dificuldade de se obter um amplo intervalo de queima e, ao mesmo tempo, uma redução da temperatura inicial de gresificação. De fato, a relação entre temperatura e composição pode levar a distorções, empenamento ou surgimento de bolhas, nas peças queimadas.

No presente trabalho, testou-se a substituição parcial dos feldspatos por outros fundentes. Empregaram-se matériasprimas que apresentavam em sua composição a wolastonita e o espodumênio, além do vidro sodo-cálcico, proveniente da reciclagem de embalagens vítreas. Embora alguns desses fundentes venham sendo utilizados mais recentemente na indústria de revestimentos, como porcelanatos, um estudo não foi ainda realizado para esta porcelana. O principal prérequisito para seleção desses fundentes foi os baixíssimos teores de óxidos cromóforos como ferro e titânio, o que é necessário aos produtos de elevado índice de alvura. O espodumênio apresenta interesse por apresentar um óxido muito fundente com os silicatos, como o óxido de lítio. A wolastonita foi escolhida por fornecer grande quantidade de $\mathrm{CaO}$, que pode contribuir à fundência da massa na presença de outros óxidos, já que a wolastonita pura não pode ser considerada um fundente, já que apresenta temperatura de fusão $1540{ }^{\circ} \mathrm{C}$. No entanto, espera-se que $\mathrm{CaO}$, ao reagir com outros óxidos, forme fase líquida de maior viscosidade, aumentando a resistência à deformação piroplástica das peças. Por fim, o vidro se destaca por ser um material reciclado que atua em uma massa cerâmica propiciando uma forte redução da temperatura de queima, devido à presença de óxido de sódio, levando ao desenvolvimento de novas fases, notadamente a anortita na porcelana dura [9-12].

\section{MATERIAIS E MÉTODOS}

A formulação de base foi $50 \%$ osso calcinado, $25 \%$ caulim e $25 \%$ feldspato, em percentual mássico. Nas outras formulações de teste, utilizou-se $15 \%$ feldspato e $10 \%$ fundente enérgico (espodumênio ou wolastonita ou vidro), $50 \%$ osso calcinado e $25 \%$ caulim, como mostra a Tabela I.

$\mathrm{O}$ fundente denominado espodumênio é um rejeito de rocha beneficiada rica no mineral espodumênio $\left(\mathrm{LiAlSi}_{2} \mathrm{O}_{6}\right)$, contendo ainda quartzo e albita. A wolastonita é um silicato de cálcio, fornecido pela empresa NYCO Minerals. O vidro é proveniente da limpeza e moagem de embalagens transparentes, produzidas com vidro sodo-cálcico. Todos os fundentes foram moídos a úmido em moinho de bolas de alumina.

A Tabela II apresenta a composição química das matérias-primas utilizadas, realizada por fluorescência de raios X (Shimadzu XRF-1800), com exceção do óxido de lítio, cuja quantidade foi estimada por análise petrográfica e analisada por absorção atômica [15]. As fases cristalinas foram determinadas por difração de raios X (Phillips X'pert MPD) como mostrado na Tabela III. A Tabela IV apresenta a distribuição granulométrica determinada por difração laser (Cilas 1180). Esta análise foi feita após moagem, até as matérias-primas serem passante em peneira ABNT malha 325 (abertura de $45 \mu \mathrm{m}$ ).

O pó de osso utilizado é proveniente de empresa que produz artigos artesanais, sendo um resíduo do corte e polimento de ossos bovinos, previamente limpos com soda cáustica $(\mathrm{NaOH})$. Em laboratório o pó de osso foi calcinado a $1000{ }^{\circ} \mathrm{C}$ e moído até que $90 \%$ das partículas (retidas em peneira) corresponderam a dimensões menores que $14 \mu \mathrm{m}$, conforme as recomendações [13, 14], citadas em artigo anterior [3].

As formulações compostas pelas matérias-primas foram misturadas a úmido em moinho, dispersas com silicato de sódio (solução em água) e passadas em peneira $\mathrm{ABNT}$ malha 325. A seguir, a massa foi seca a $110{ }^{\circ} \mathrm{C}$ em estufa, umidificada com água ( $8 \%$ em massa) e granulada por peneiramento em malha ABNT $20(0,84 \mathrm{~mm})$. Na seqüência,

Tabela I - Proporção das matérias-primas nas formulações.

[Table I - Proportion of raw materials in the bodies.]

\begin{tabular}{|c|c|c|c|c|c|c|}
\hline$\%$ em massa & Caulim & $\begin{array}{c}\text { Osso } \\
\text { calcinado }\end{array}$ & $\begin{array}{l}\text { Feldspato } \\
\text { Potássico }\end{array}$ & $\begin{array}{l}\text { Espodu- } \\
\text { mênio }\end{array}$ & $\begin{array}{l}\text { Wolas- } \\
\text { tonita }\end{array}$ & Vidro \\
\hline $\begin{array}{c}\text { Formulação com } \\
\text { Feldspato }\end{array}$ & 25 & 50 & 25 & - & - & - \\
\hline $\begin{array}{l}\text { Formulação com } \\
\text { espodumênio }\end{array}$ & 25 & 50 & 15 & 10 & - & - \\
\hline $\begin{array}{l}\text { Formulação com } \\
\text { Wolastonita }\end{array}$ & 25 & 50 & 15 & - & 10 & - \\
\hline $\begin{array}{l}\text { Formulação com } \\
\text { Vidro }\end{array}$ & 25 & 50 & 15 & - & - & 10 \\
\hline
\end{tabular}


Tabela II - Composição química das matérias-primas.

[Table II - Chemical composition of raw materials.]

\begin{tabular}{ccccccc}
\hline (\%) em massa & Caulim & $\begin{array}{c}\text { Osso } \\
\text { calcinado }\end{array}$ & $\begin{array}{c}\text { Espodu- } \\
\text { mênio }\end{array}$ & $\begin{array}{c}\text { Feldspato } \\
\text { Potássico }\end{array}$ & $\begin{array}{c}\text { Wolas- } \\
\text { tonita }\end{array}$ & Vidro \\
\hline $\mathrm{SiO}_{2}$ & 46,96 & 0,65 & 78,32 & 66,2 & 47,61 & 73,96 \\
$\mathrm{Al}_{2} \mathrm{O}_{3}$ & 38,05 & 0,8 & 13,66 & 16,54 & 0,11 & 1,59 \\
$\mathrm{Fe}_{2} \mathrm{O}_{3}$ & 0,46 & 0,12 & 0,24 & 0,15 & 0,14 & 0,18 \\
$\mathrm{MgO}$ & - & 1,1 & - & - & - & 0,2 \\
$\mathrm{CaO}$ & 0,02 & 52,2 & 0,44 & 0,36 & 48,66 & 8,37 \\
$\mathrm{Na}_{2} \mathrm{O}$ & 0,03 & 2,1 & 1,16 & 0,89 & & 14,14 \\
$\mathrm{~K}_{2} \mathrm{O}$ & 1,14 & 0,07 & 2,41 & 14,66 & 0,03 & 0,84 \\
$\mathrm{Li}_{2} \mathrm{O}$ & - & - & $2,5 *$ & - & - & - \\
$\mathrm{TiO}_{2}$ & 0,03 & - & - & 0,03 & - & - \\
$\mathrm{P}_{2} \mathrm{O}_{5}$ & 0,108 & 40,5 & 0,11 & 0,15 & - & - \\
$\mathrm{Outros}$ & 0,03 & 0,2 & 0,94 & 0,64 & 0,35 & 0,71 \\
$\mathrm{PF}$ & 13,2 & 2,3 & 0,20 & 0,38 & 3,1 & 0,01 \\
\hline
\end{tabular}

*realizado por absorção atômica; $P F=$ Perda ao fogo

Tabela III - Fases minerais em cada matéria-prima. Listadas as fases de maior importância. [Table III - Raw material phase analysis. Major phases are showed.]

\begin{tabular}{cccc}
\hline Constituintes Presentes & & & $\begin{array}{c}\text { DRX-JCPDS } \\
\text { Número do arquivo }\end{array}$ \\
\hline Caulim & Caolinita & $\mathrm{Al}_{2} \mathrm{Si}_{2} \mathrm{O}_{5}(\mathrm{OH})_{4}$ & $14-164$ \\
& Quartzo & $\mathrm{SiO}_{2}$ & $05-490$ \\
& Muscovita & $\mathrm{KAl}_{2} \mathrm{Si}_{3} \mathrm{AlO}_{10}(\mathrm{OH})_{2}$ & $03-0849$ \\
& Quartzo & $\mathrm{SiO}_{2}$ & $05-490$ \\
Feldspato & Microclínio & $\mathrm{KAlSi}_{3} \mathrm{O}_{8}$ & $22-675$ \\
& Albita & $\mathrm{NaAlSi}_{3} \mathrm{O}_{8}$ & $01-0739$ \\
& Espodumênio & $\mathrm{LiAlSi}_{2} \mathrm{O}_{6}$ & $33-0786$ \\
Espodumênio & Quartzo & $\mathrm{SiO}_{2}$ & $05-490$ \\
& Albita & $\mathrm{NaAlSi}_{3} \mathrm{O}_{8}$ & $01-0739$ \\
& Wolastonita & $\mathrm{CaSiO}_{3}$ & $19-0249$ \\
Pó de ossos & Wolastonita & $\mathrm{Ca}(\mathrm{OH})_{2} \cdot 3 \mathrm{Ca}_{3}\left(\mathrm{PO}_{4}\right)_{2}$ & $09-432$ \\
\hline
\end{tabular}

Tabela IV - Distribuição granulométrica das matériasprimas, após moagem a úmido.

[Table IV - Raw materials particle size distribution after wet milling.]

\begin{tabular}{cccc}
\hline \multicolumn{4}{c}{ Distribuição Granulométrica da matéria-prima $(\mu \mathrm{m})$} \\
Amostra & $10 \%<(\mu \mathrm{m})$ & $90 \%<(\mu \mathrm{m})$ & $\begin{array}{c}\text { Diâmetro } \\
\text { Médio }(\mu \mathrm{m})\end{array}$ \\
\hline Osso & 0,52 & 11,21 & 4,16 \\
calcinado & & 14,26 & 7,89 \\
Caulim & 2,35 & 41,49 & 22,5 \\
Feldspato & 2,03 & 37,68 & 15,11 \\
Espodumênio & 1,28 & 29,55 & 12,78 \\
Wolastonita & 1,13 & 32,3 & 19,82 \\
Vidro & 2,18 & &
\end{tabular}

as massas cerâmicas foram prensadas uniaxialmente em prensa hidráulica de simples efeito, cominuídas em gral, secas em estufa, misturadas à mão e novamente umidificadas ( $8 \%$ em peso), granuladas (em malha 20$)$ e prensadas $(\sim 30$ MPa) nas dimensões $8 \times 20 \times 60 \mathrm{~mm}^{3}$. A secagem foi de $48 \mathrm{~h}$ ao ar livre em estufa a $110^{\circ} \mathrm{C}$ por no mínimo mais $24 \mathrm{~h}$. A densidade aparente (em querosene) a seco das peças foi de $1,90 \mathrm{~g} / \mathrm{cm}^{3} \mathrm{em}$ média. Cada teste foi realizado com pelo menos 8 corpos-de-prova de cada formulação. As temperaturas de queima variaram de $1180{ }^{\circ} \mathrm{C}$ a 1280 ${ }^{\circ} \mathrm{C}$, em forno elétrico tipo mufla, sendo que os corpos-deprova das quatro formulações propostas foram queimados simultaneamente, para cada temperatura de teste. A taxa de aquecimento foi de $150{ }^{\circ} \mathrm{C} / \mathrm{h}$ e o patamar de $30 \mathrm{~min}$.

Os corpos-de-prova foram caracterizados quanto à absorção de água, retração linear (por paquímetro), densidade 
geométrica (em balança analítica e por paquímetro) e tensão de ruptura à flexão a quatro pontos [16]. O teste de deformação sobre o próprio peso foi feito com uma peça para cada condição de teste [17]. A microestrutura foi observada em microscópio eletrônico de varredura Jeol-JSM 5800, com microanálise por EDS. As amostras foram preparadas por polimento (com lixas em grana crescente, finalizandose com suspensão de alumina em água), seguido ou não de ataque ácido (HF 20\%, em diferentes tempos) para remoção da fase vítrea. Os testes de cone de fusão foram realizados com os fundentes puros, com taxa de aquecimento $150{ }^{\circ} \mathrm{C}$ até $1240{ }^{\circ} \mathrm{C}$, com patamar de $30 \mathrm{~min}$.

\section{RESULTADOS E DISCUSSÃO}

Foram analisados a curva de gresificação, os cones de fusão, a deformação piroplástica sobre o próprio peso, a dilatação térmica, a resistência mecânica e a microestrutura, juntamente com a análise das fases após a queima. Os testes foram realizados para todas as formulações citadas na Tabela I.

Avaliação da gresificação, cones de fusão e deformação piroplástica

A Tabela V mostra os resultados da caracterização tecnológica, sendo os mesmos discutidos por meio das Figs. 1 a 4, nas quais estão relacionadas as curvas de gresificação para as formulações com os fundentes testados.

Destacam-se nas Figs. 1-4 os intervalos de queima para cada formulação, os quais são formados por valores de absorção de água abaixo de $0,5 \%$. O feldspato utilizado propiciou menor fundência em relação às formulações de misturas de feldspato com os outros fundentes. A formulação com feldspato alcançou a gresificação desejada somente a partir de $1260{ }^{\circ} \mathrm{C}$ (Fig. 1). Isto pode ser explicado por se tratar de um feldspato potássico, constituído principalmente

Tabela V - Caracterização tecnológica da peças queimadas.

[Table V-Technical characterization of fired bodies.]

\begin{tabular}{|c|c|c|c|c|}
\hline $\begin{array}{l}\text { Temperatura } \\
\qquad\left(\mathrm{C}^{\circ}\right)\end{array}$ & $\begin{array}{c}\text { Absorção } \\
\text { de água } \\
(\%)\end{array}$ & $\begin{array}{c}\text { Retração } \\
\text { linear } \\
(\%)\end{array}$ & $\begin{array}{c}\text { Densidade } \\
\text { aparente } \\
\left(\mathrm{g} / \mathrm{cm}^{3}\right)\end{array}$ & $\begin{array}{c}\sigma_{\mathrm{f}} \\
(\mathrm{MPa})\end{array}$ \\
\hline \multicolumn{5}{|l|}{ Formulação com } \\
\hline 1180 & 11,22 & 6,88 & 1,97 & $36,1 \pm 3,8$ \\
\hline 1200 & 0,26 & 10,94 & 2,29 & $57,4 \pm 6,5$ \\
\hline 1220 & 0,04 & 13,11 & 2,38 & $77,0 \pm 9,3$ \\
\hline 1240 & 0,10 & 12,99 & 2,39 & $72,0 \pm 9,4$ \\
\hline 1260 & 0,00 & 12,62 & 2,37 & $75,5 \pm 5,5$ \\
\hline 1280 & 0,09 & 12,37 & 2,25 & $60,7 \pm 6,8$ \\
\hline \multicolumn{5}{|c|}{ Formulação com Vidro } \\
\hline 1200 & 4,21 & 10,49 & 2,10 & $46,5 \pm 3,5$ \\
\hline 1220 & 0,67 & 12,30 & 2,24 & $61,7 \pm 7,0$ \\
\hline 1240 & 0,05 & 13,55 & 2,27 & $54,3 \pm 6,2$ \\
\hline 1260 & 0,00 & 14,62 & 2,33 & $56,5 \pm 5,5$ \\
\hline 1280 & 0,18 & 13,53 & 2,24 & $63,5 \pm 7,4$ \\
\hline \multicolumn{5}{|c|}{ Formulação com Wolastonita } \\
\hline 1180 & 2,33 & 11,62 & 2,29 & $53,3 \pm 9,3$ \\
\hline 1200 & 0,01 & 13,67 & 2,43 & $62,4 \pm 8,1$ \\
\hline 1220 & 0,04 & 13,23 & 2,46 & $73,9 \pm 4,1$ \\
\hline 1240 & 0,02 & 13,10 & 2,34 & $58,8 \pm 8,2$ \\
\hline 1260 & 0,03 & 12,66 & 2,28 & $53,0 \pm 9,1$ \\
\hline 1280 & 0,00 & 12,47 & 2,25 & $52,6 \pm 4,3$ \\
\hline \multicolumn{5}{|c|}{ Formulação com Feldspato } \\
\hline 1240 & 1,22 & 8,80 & 2,17 & $41,1 \pm 4,3$ \\
\hline 1260 & 0,06 & 9,65 & 2,22 & $54,0 \pm 4,1$ \\
\hline 1280 & 0,05 & 9,59 & 2,16 & $48,1 \pm 4,7$ \\
\hline
\end{tabular}




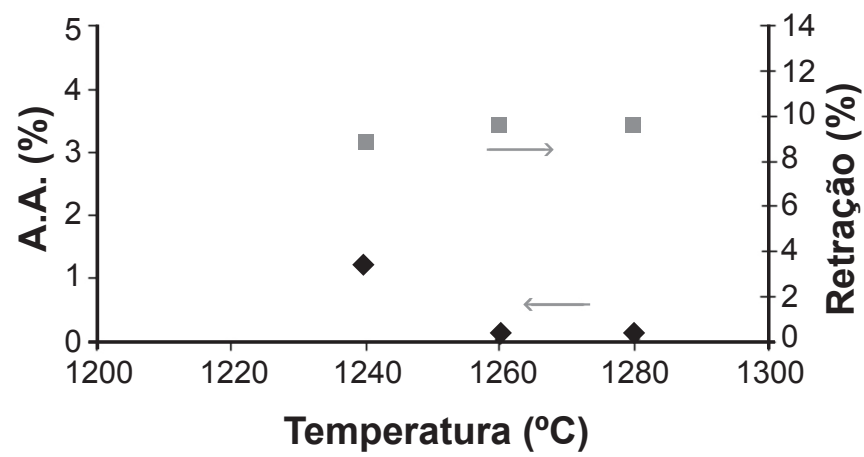

Figura 1: Retração linear e absorção de água (A.A.) em função da temperatura. Formulação com feldspato.

[Figure 1: Linear shrinkage and water absorption (A.A.) as a function of firing temperature. Feldspar composition.]

por microclínio. Feldspatos alcalinos que possuem teores mais elevados de albita apresentaram gresificação entre $1220^{\circ} \mathrm{C}$ e $1240{ }^{\circ} \mathrm{C}$, em outros estudos $[3,6]$.

A adição de vidro ao feldspato (formulação com vidro) resultou em uma diminuição de $20^{\circ} \mathrm{C}$ da temperatura de início de gresificação, como mostra a Fig. 2. Em contrapartida, em $1280^{\circ} \mathrm{C}$ as peças já começaram a mostrar a expansão da porosidade, ainda de forma incipiente, indicando que a queima não deve ser feita em temperaturas superiores a essa temperatura. Apesar de o vidro ser um fundente enérgico, principalmente devido à presença de óxido de sódio $(\sim 14 \%$ em massa) $[9,10]$, sua mistura com o feldspato propicia um intervalo de queima suficientemente amplo para produção comercial dessa formulação, uma vez que é característico de formulações da porcelana de ossos apresentarem curtos intervalos de queima [1]. Outros trabalhos, utilizando-se de fundentes convencionais como feldspatos alcalinos (mais ricos em sódio do que o feldspato utilizado neste trabalho) e nefelina sienítico, mostraram intervalos de queima similares e, em alguns casos, mais reduzidos $[3,6,18]$. Portanto, a adição de maiores teores dos óxidos fundentes presentes no vidro, explica a menor temperatura de gresificação dessa formulação.

As Figs. 3 e 4 mostram a gresificação para as formulações com wolastonita e com espodumênio, respectivamente. O

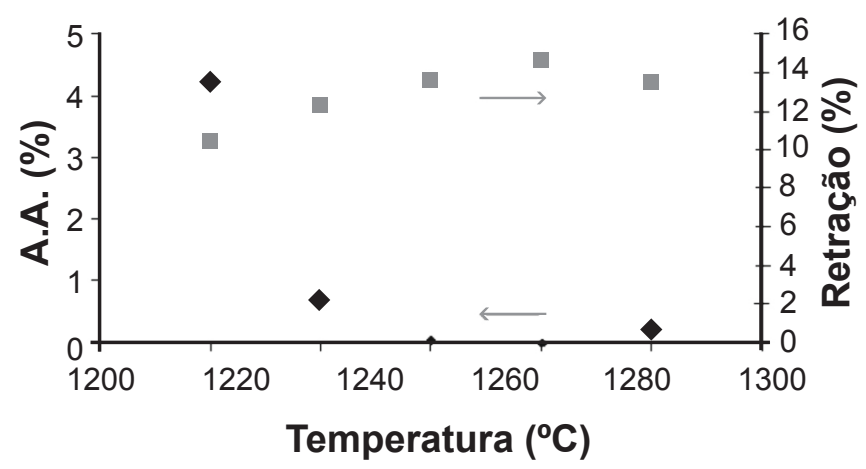

Figura 2: Retração linear e absorção de água (A.A.) em função da temperatura. Formulação com feldspato + vidro.

[Figure 2: Linear shrinkage and water absorption (A.A.) as a function of firing temperature. Feldspar + glass composition.]

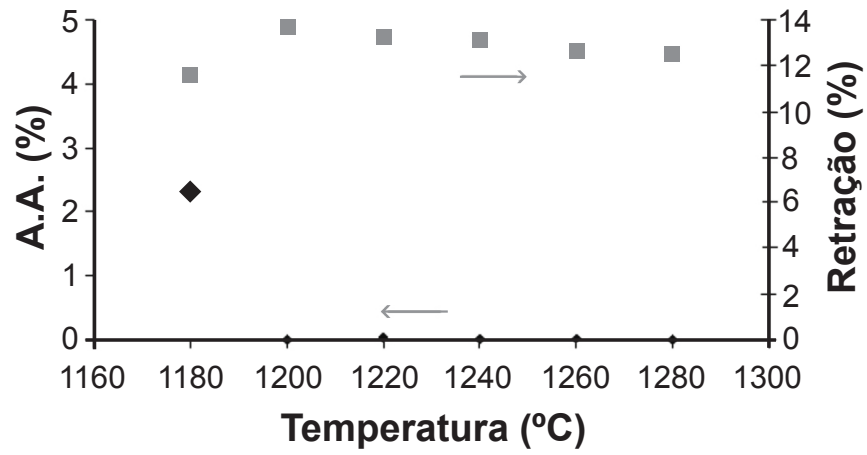

Figura 3: Retração linear e absorção de água (A.A.) em função da temperatura. Formulação com feldspato + wolastonita.

[Figure 3: Linear shrinkage and water absorption (A.A.) as a function of firing temperature. Feldspar + wollastonite composition.]

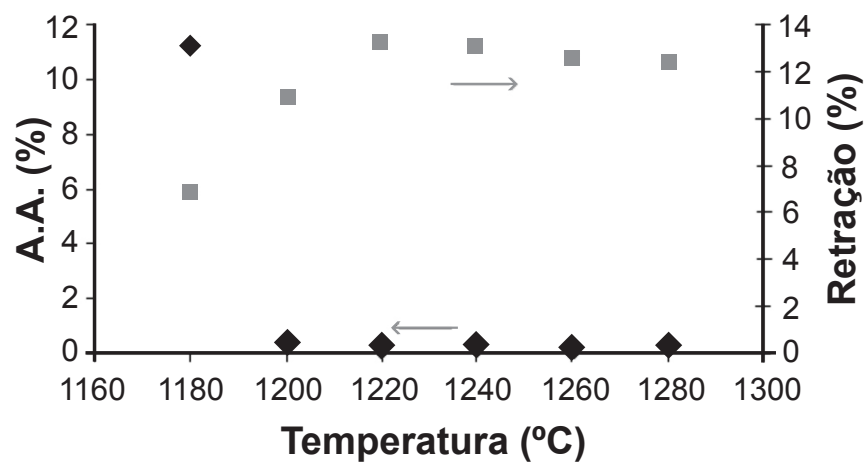

Figura 4: Retração linear e absorção de água (A.A.) em função da temperatura. Formulação com feldspato + espodumênio.

[Figure 4: Linear shrinkage and water absorption (A.A.) as a function of firing temperature. Feldspar + spodumene composition.]

resultado é bastante interessante, uma vez que se obteve um amplo intervalo de queima. Esses fundentes possibilitaram também uma significativa redução da temperatura de queima, cerca de $60^{\circ} \mathrm{C}$, em comparação com a formulação somente com feldspato.

Procura-se, a seguir, explicar o comportamento de cada fundente, apresentando-se as semelhanças e diferenças entre eles. As formulações com vidro e espodumênio atuaram de maneira a promover a formação de fase vítrea em menor temperatura, bem como a reduzir a viscosidade da mesma, como é esperado em decorrência da presença de óxidos alcalinos em vidros silicosos, os quais modificam as propriedades da fase vítrea, de modo a acelerar a densificação por fluxo viscoso [19]. Assim, o pequeno íon lítio apresenta o maior coeficiente de difusão, explicando a maior fundência do espodumênio. É conhecido que os íons alcalinos apresentam os maiores coeficientes de difusão em silicatos líquidos [20]. Destaca-se que a formulação com espodumênio em $1180{ }^{\circ} \mathrm{C}$ mostrou baixa retração e elevada porosidade aberta, esta, expressa em termos de absorção de água (Fig.4); no entanto, em $1200^{\circ} \mathrm{C}$ se apresenta plenamente gresificada. $\mathrm{O}$ espodumênio funde a $\sim 1420^{\circ} \mathrm{C}$, mas existem dois eutéticos em $\sim 1020^{\circ} \mathrm{C}$ conforme o diagrama $\mathrm{Li}_{2} \mathrm{O}-\mathrm{SiO}_{2}$. 
O eutético em aproximadamente $15 \% \mathrm{Li}_{2} \mathrm{O}-79 \% \mathrm{SiO}_{2}-8 \%$ $\mathrm{Al}_{2} \mathrm{O}_{3}$ se encontra em temperatura inferior a $1000{ }^{\circ} \mathrm{C}$ [21]. Portanto, espera-se que na mistura com as demais matériasprimas, determinados pontos da microestrutura apresentem, ao menos teoricamente, a formação de fase líquida viscosa. O mesmo pode ocorrer quando se utiliza vidro como fundente: no diagrama $\mathrm{Na}_{2} \mathrm{O}-\mathrm{SiO}_{2}$, encontram-se dois eutéticos em temperaturas menores que $1000{ }^{\circ} \mathrm{C}$ e para aproximadamente $7 \% \mathrm{Na}_{2} \mathrm{O}-78 \% \mathrm{SiO}_{2}-15 \% \mathrm{Al}_{2} \mathrm{O}_{3}$, o eutético está abaixo de $1000{ }^{\circ} \mathrm{C}$ [22]. Além disso, o vidro sodo-cálcico já apresenta viscosidade bastante baixa para temperaturas bem inferiores a $1000^{\circ} \mathrm{C}[19]$.

No caso da formulação com wolastonita a explicação de sua plena gresificação já a $1200{ }^{\circ} \mathrm{C}$ pode ser por dois caminhos: um que considera como fator determinante a presença dos óxidos fundentes mesmo em baixas quantidades (como alcalinos e $\mathrm{Fe}_{2} \mathrm{O}_{3}$ ) e outro que considera o óxido de fósforo formando fases metaestáveis. A wolastonita comercial apresenta fusão a $\sim 1450{ }^{\circ} \mathrm{C}$, não podendo ser considerada um fundente, como demonstrou o teste de cone de fusão (Fig. 5). Na formulação da porcelana, os principais componentes formam o eutético de menor temperatura para a proporção de $25 \% \mathrm{CaO}-60 \% \mathrm{SiO}_{2}-15 \% \mathrm{Al}_{2} \mathrm{O}_{3}$ em $1165{ }^{\circ} \mathrm{C}$ [22]. Entretanto, considerando-se os dados das Tabelas I e II, a composição global da formulação com wolastonita localizase no triângulo de compatibilidade $\mathrm{CaO} . \mathrm{SiO}_{2}-3 \mathrm{CaO} .2 \mathrm{SiO}_{2}-$ $2 \mathrm{CaO} \cdot \mathrm{Al}_{2} \mathrm{O}_{3} \cdot \mathrm{SiO}_{2}$, com a formação de fase líquida somente a $1310{ }^{\circ} \mathrm{C}$. É interessante notar que o acréscimo de $\mathrm{CaO}$ aumentaria a refratariedade em relação a composição global da porcelana de ossos (no diagrama de equilíbrio $\mathrm{CaO}-\mathrm{Al}_{2} \mathrm{O}_{3}-\mathrm{SiO}_{2}$ ). Portanto, o comportamento na queima da formulação com wolastonita pode ser explicado pela presença dos constituintes minoritários e heterogeneidades na microestrutura (devido à mistura aleatória do material moído), cuja composição puntual possa favorecer, ao acaso,à formação de fase vítrea. Isto reforça a importância da reação de óxidos fundentes com a sílica, embora esses estejam em pequenas quantidades na formulação. A segunda explicação proposta faz referência à maior quantidade de óxido de cálcio ou a presença do mesmo em uma forma mais reativa, como silicato de cálcio, a qual pode favorecer a outra rota de formação das fases finais, restando um maior teor de óxido de fósforo livre. Este pode levar a uma gresificação em menores temperaturas, por meio de compostos de fósforo de menor temperatura de fusão, os quais não aparecem no produto final $[7,8,14]$.

O teste de cone de fusão (Fig. 5) ilustra que a wolastonita pura é bem mais refratária em relação aos outros fundentes. No entanto, propicia à formulação de porcelana, uma gresificação similar à do espodumênio. $\mathrm{O}$ vidro não aparece na referida figura, por já perder o formato de cone, na temperatura do teste $\left(1240{ }^{\circ} \mathrm{C}\right)$. O teste de simples deformação sobre o próprio peso (sag test) mostrou que não ocorreu deformação piroplástica das peças, para os intervalos de temperatura estudados. Portanto, a viscosidade da fase vítrea é suficientemente alta, para conter a deformação das peças, para todos fundentes utilizados.

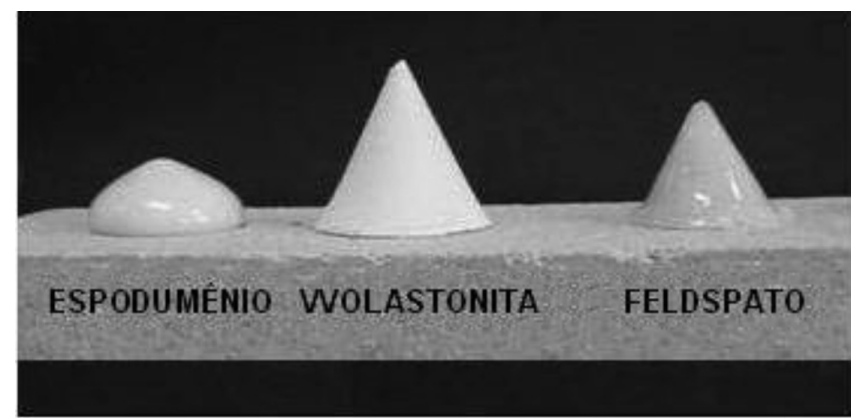

Figura 5: Teste de cone de fusão para formulações de $100 \%$ de fundente. Taxa de $150{ }^{\circ} \mathrm{C} / \mathrm{h}$, temperatura máxima $1240{ }^{\circ} \mathrm{C}$ e 30 min de patamar.

[Figure 5: Fusion cone test for compositions of $100 \%$ flux. Temperature ramp of $150^{\circ} \mathrm{C} / \mathrm{h}$; fired at $1240{ }^{\circ} \mathrm{C}$ for $30 \mathrm{~min}$.]

\section{Expansão térmica linear}

As curvas de expansão térmica para as formulações estudadas são mostradas na Fig. 6. Nota-se que as formulações apresentaram um comportamento bastante similar entre si. O cálculo do coeficiente de expansão linear, inferido para as temperaturas mínima de $24^{\circ} \mathrm{C}$ e máxima de $400{ }^{\circ} \mathrm{C}$ apresentou como resultado $9,7.10^{-6} \mathrm{~K}^{-1} ; 9,0.10^{-6} \mathrm{~K}^{-1}$; $9,6.10^{-6} \mathrm{~K}^{-1}$ e $9,2.10^{-6} \mathrm{~K}^{-1}$, para as formulações com feldspato, espodumênio, vidro e wolastonita, respectivamente. Esses valores são próximos ao valor teórico $\left(\sim 8,4.10^{-6} \mathrm{~K}^{-1}\right)$ a partir do cálculo por "regra das misturas" das fases constituintes, cuja proporção é de aproximadamente $40 \%$ fosfato tricálcico- $\beta, 30 \%$ anortita e $30 \%$ vidro [8]. A pequena diferença entre os valores medidos e o teórico é esperada devido à presença de quartzo em algumas matériasprimas e/ou por variações das quantidades de fases. A presença de espodumênio pouco modifica a expansão térmica de sua formulação. Portanto, pode-se deduzir que praticamente todo espodumênio foi decomposto, de modo que provavelmente seus óxidos formadores se incorporaram à fase vítrea. Isto foi confirmado pela análise de difração

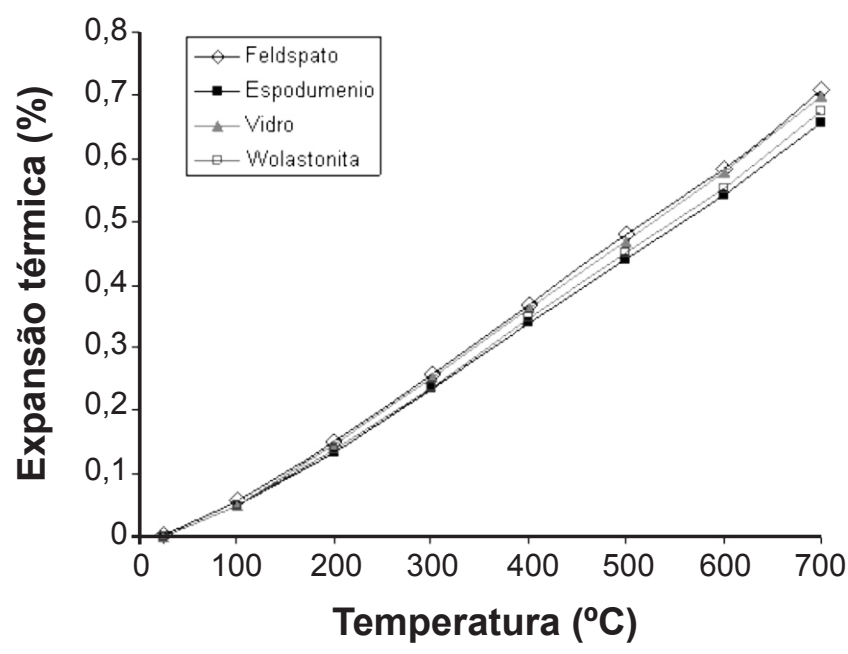

Figura 6: Expansão térmica linear.

[Figure 6: Linear thermal expansion.] 
que mostrou apenas fosfato tricálcico- $\beta$, quartzo e anortita, na análise difratométrica da formulação com espodumênio após a queima. Observa-se que como os fundentes testados não alteram significativamente a expansão térmica das peças produzidas, não se torna necessário o desenvolvimento de vidrados especiais para essas formulações.

\section{Resistência mecânica e análise microestrutural}

A resistência mecânica dos corpos-de-prova medidos por flexão é apresentada na Tabela V. Em princípio, todas as formulações atingiram resistências mecânicas suficientemente altas. A resistência mecânica de uma porcelana é função principalmente das fases formadas e da porosidade. Estas características foram analisadas na investigação microestrutural. A Fig. 7 mostra as microestruturas das formulações queimadas a $1240{ }^{\circ} \mathrm{C}$. Nota-se que existe uma relação praticamente direta entre o tamanho de poro e a resistência mecânica (Tabela V). Considerando-se também a porosidade relativa mostrada na Fig. 7, a relação com a resistência mecânica também se mantém. Ou seja, quanto maior o tamanho de poro e a quantidade de porosidade, menor a resistência mecânica. Ressalva-se que o fator mais importante seja o tamanho de poro/trinca na determinação do chamado defeito crítico ou controlador da resistência mecânica, conforme a teoria da elasticidade linear para fratura mecânica [23]. A porosidade interfere pelo fato que, em geral, quanto maior esta, maior a probabilidade de existirem poros de tamanhos maiores [23, 24]. Referente às microestruturas (Fig. 7), observa-se que a formulação com feldspato apresenta maior tamanho de poro, seguido da formulação com wolastonita, enquanto a formulação com espodumênio e a com vidro apresentam tamanhos de poro semelhantes. Neste caso, considerando-se as duas últimas formulações, o fator determinante da resistência mecânica pode ser uma diferença na quantidade de fases cristalinas, e/ou, simplesmente, na porosidade total.

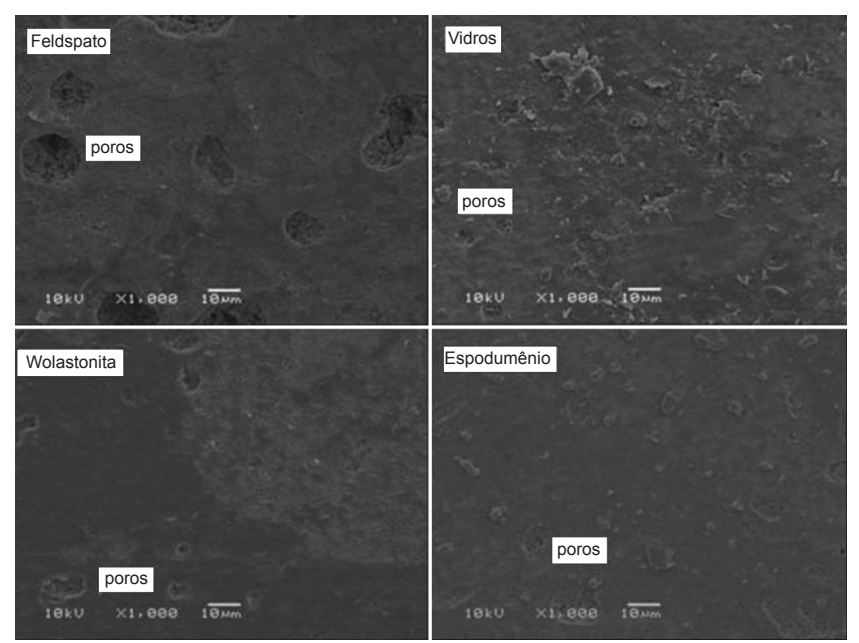

Figura 7: Micrografias obtidas por microscopia eletrônica de varredura, sem ataque químico. Formulações com feldspato, vidro, wolastonita ou espodumênio queimadas a $1240{ }^{\circ} \mathrm{C}$.

[Figure 7: SEM micrographs. No chemical etching. Feldspar, waste glass, wollastonite or spudomene compositions fired at $1240{ }^{\circ} \mathrm{C}$.]
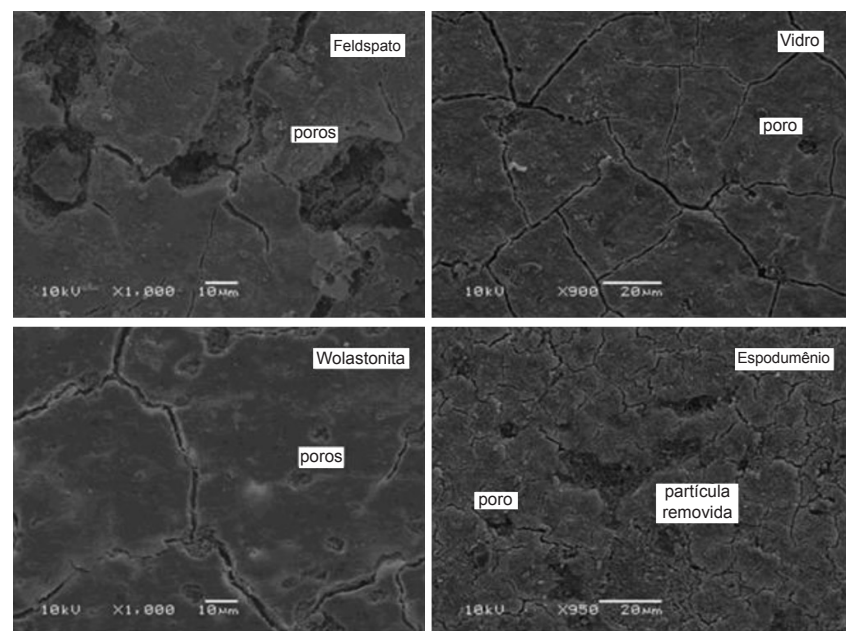

Figura 8: Micrografias obtidas por microscopia eletrônica de varredura, com ataque químico (HF 20\%, 20 s). Formulações com feldspato, vidro, wolastonita ou espodumênio queimadas a $1240{ }^{\circ} \mathrm{C}$. [Figure 8: SEM micrographs. Chemical etching (HF 20\%, $20 \mathrm{~s}$ ). Feldspar, waste glass, wollastonite or spudomene compositions fired at $\left.1240^{\circ} \mathrm{C}.\right]$

Na Fig. 9, utilizando-se de ataque ácido para remoção da fase vítrea, nota-se uma microestrutura fraturada para todas as formulações. Isto ocorre em consequência da tensão gerada devido à diferença de expansão térmica entre a matriz e os clusters de grãos de fosfato tricálcico- $\beta$ (coeficiente de expansão térmica linear de $\sim 12.10^{-6} \mathrm{k}^{-1}$ ) [8]. Observa-se novamente a diferença de tamanho dos poros presentes, notadamente, maiores para a formulação com feldspato. A indicação de "partícula removida", mostrada na microestrutura da formulação com espodumênio referese à localização de uma partícula removida em decorrência do polimento, na preparação da amostra para microscopia eletrônica de varredura. O tamanho dos referidos clusters de fosfato tricálcico- $\beta$ é a principal diferença entre as formulações estudadas (Fig. 8). Essa variação de tamanho pode ser explicada pelas diferenças das fases presentes e, conseqüentemente, na quantidade de fase vítrea, na temperatura de início da fluidificação e na viscosidade da fase vítrea. Estes fatores alteram a capacidade de acomodação das tensões geradas pela diferença de expansão térmica entre as fases. Alternativamente, ocorre também, nas formulações, diferenças na quantidade e tamanho de grão da fase fosfato tricálcico- $\beta$. A dificuldade de se obter maiores intervalos de queima para porcelana de ossos pode ser explicada pela sua baixa quantidade de quartzo. Este sofre dissolução gradual durante a queima, elevando a quantidade de sílica na fase vítrea, o que garante maiores viscosidades e a constância dimensional das peças de porcelanas quartzosas em maiores temperaturas de queima $[25,26]$. Em princípio, o espodumênio, por possuir quartzo, aumenta o teor desse mineral na composição final - não se descartando a influência dele sobre a viscosidade da fase vítrea ou no auxílio à formação de uma estrutura mais rígida. Entretanto, na análise microestrutural raramente se observa um grão de quartzo (Fig. 9). Além disso, o grão de quartzo 


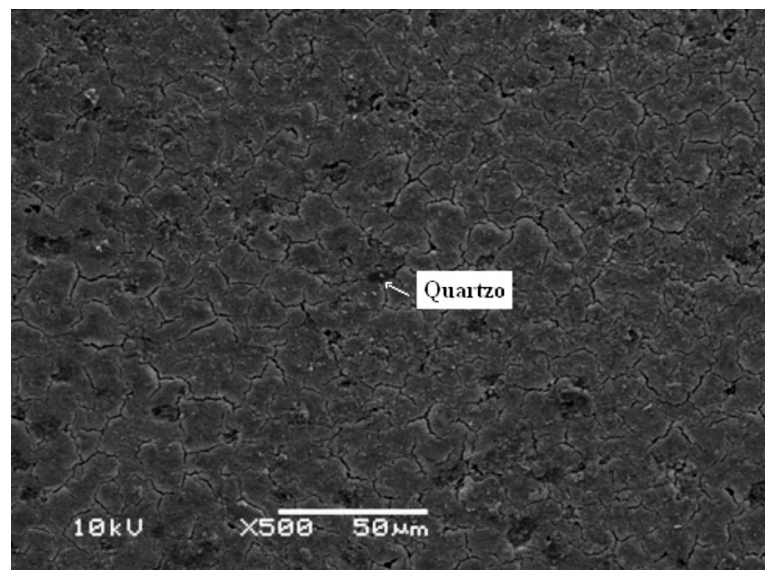

Figura 9: Micrografia obtida por microscopia eletrônica de varredura, com ataque químico (HF 20\%, 20 s). Formulação com espodumênio a $1240^{\circ} \mathrm{C}$.

[Figure 9: SEM micrograph. Chemical etching (HF 20\%, 20 s). Spodumene composition fired at $1240{ }^{\circ} \mathrm{C}$.]

não apresenta sinais de dissolução, comumente presente em porcelanas quartzosas. A ausência de dissolução também foi constatada em outros trabalhos [3,8], nos quais o quartzo foi adicionado como matéria-prima em teores de $\sim 6 \%$. Pela análise da Fig. 9, o quartzo ocorre apenas como contaminante nas matérias-primas, de modo que não se espera influência significativa dessa fase sobre o comportamento dos corposde-prova durante a queima.

\section{Considerações finais}

Em condições de queima rápida as composições obtidas com misturas de feldspato potássico e fundentes enérgicos atuaram sem atingir o equilíbrio. Verificou-se uma ampla variação dos teores dos principais elementos formadores da fase vítrea (Ca, Si, Al, Na) na análise via EDS [7]. Para explicar as menores temperaturas de queima e ao mesmo tempo os amplos intervalos de queima obtidos, propõese que os fundentes testados devem começar a atuar em temperaturas menores que às da formulação convencional (somente com feldspato), de modo a acelerar as reações de sinterização, mas sem modificar significativamente a tensão superficial da fase vítrea. Esta hipótese é baseada no fato do espodumênio ter a particularidade de atuar como um fundente enérgico e, ao mesmo tempo, aumentar a tensão superficial da fase vítrea [27]. Por outro lado, a wolastonita aumenta a quantidade de cálcio na fase vítrea, o que aumenta também a tensão superficial, de modo a compensar a atuação dos íons alcalinos fundentes [19]. No caso do vidro, considera-se o aporte de sódio mais importante, reduzindo a temperatura de sinterização, mas levando à condição de gresificação próxima a de feldspatos alcalinos sódicos. Portanto, propõese que os fundentes testados - espodumênio ou wolastonita - podem propiciar uma redução da temperatura de gresificação, sem comprometer a resistência à deformação piroplástica, por dois caminhos: o aumento do teor de $\mathrm{Ca}^{++}$ na fase vítrea, o que também melhora a distribuição de $\mathrm{Ca}^{++}$ na microestrutura, pois não depende apenas da difusão a partir das partículas de hidroxiapatita; e o maior coeficiente de difusão de um íon pequeno como o $\mathrm{Li}^{+}$. No entanto, não se consegue demonstrar experimentalmente essas suposições devido à ampla variação de percentual do cálcio na fase vítrea, dentro de uma mesma formulação. O mesmo vale para o lítio, elemento não detectável via EDS.

\section{CONCLUSÕES}

A utilização de fundentes enérgicos (em substituição parcial ao feldspato potássico) como a wolastonita e o espodumênio, permitiu ampliar o intervalo de gresificação, alcançando menores temperaturas de queima, sem propiciar a deformação piroplástica das peças. A wolastonita possibilitou o aumento da viscosidade da fase vítrea pelo aporte de óxido de cálcio, o que possibilitou um maior intervalo de queima. A redução da temperatura de queima é explicada pela reação do óxido de cálcio com a sílica, a alumina e os óxidos alcalinos, mesmo estes presentes em pequenas quantidades, o que ressalta sua importância. $\mathrm{O}$ espodumênio fornece o íon de lítio, cuja atuação em silicatos apresenta a particularidade de reduzir a temperatura de queima, sem diminuir a tensão superficial da fase vítrea. $\mathrm{O}$ uso de vidro reciclado permitiu a redução da temperatura de queima em relação ao feldspato potássico. No entanto, o intervalo e a temperatura de queima ficaram similares aos de formulações com feldspatos sódicopotássicos. Isto prova a predominância do efeito do óxido de sódio sobre o óxido de cálcio, considerando-se que este está presente em quantidades menores no vidro utilizado.

\section{AGRADECIMENTOS}

Ao Dr. H. C. M. Lengler e ao coordenador do LACER/ UFRGS Prof. Dr. C. P. Bergmann.

\section{REFERÊNCIAS}

[1] P. Rado, Bone china, Ceramics Monographs - A Handbook of Ceramics, Verlag Schmidt GmbH Freiburg i. Brg. (1981).

[2] S. R. Bragança, C. P. Bergmann, XVI Congresso Brasileiro de Ciência e Engenharia de Materiais (2004).

[3] S. R. Bragança, C. P. Bergmann, Cerâmica 52, 322 (2006) 205-212.

[4] S. R. Bragança, C. P. Bergmann, Industrial Ceramics 28 , 3 (2008) 189-194

[5] S. A. F. Batista, P. F. Messer, R. J. Hand, Brit. Ceram. Trans. 100, 6 (2001) 256-258.

[6] C. G. Portillo, Bol. Soc. Céram. Vidrio 38, 5 (1998) $397-$ 402.

[7] Y. Iqbal, P. F. Messer, W. E. Lee, Br. Ceram. Trans. 99, 3 (2000) 110-116.

[8] Y. Iqbal, P. F. Messer, W. E. Lee, Br. Ceram. Trans. 99, 5 (2000) 193-199.

[9] S. R. Bragança, Desenvolvimento de uma cerâmica triaxial utilizando vidro como fundente e relação entre 
microestrutura e propriedades tecnológicas, Tese de Doutorado, Universidade Federal do Rio Grande do Sul, Porto Alegre, RS (2002).

[10] S. R. Bragança, C. P. Bergmann, Mater. Res. 8, 1 (2004) 01-07.

[11] P. R. Jackson, P. Hancock, D. Cartlidge, Proc. Sustainable Waste Management and Recycling: Glass Waste, Ed. M.C. Lymbachiya, J. J. Roberts, London, Inglaterra (2004) 313-320.

[12] T. Tarvornpanich, G. P. Souza, W. E. Lee, J. Am. Ceram. Soc. 88, 5 (2005) 1302-1308.

[13] D. Basnett, P. J. Cartwrigtht, Trans. J. Brit. Ceram. Soc. 88, 5 (1989) 191-195.

[14] J. J. Cooper, Brit. Ceram. Trans. 94, 4 (1995) 165-168.

[15] H. C. M. Lengler, Controle da porosidade em fases vítreas formadas pela ação de fundentes em cerâmicas gresificadas, Tese de Doutorado, Universidade Federal do Rio Grande do Sul, Porto Alegre, RS (2006).

[16] ASTM C-133/94; ASTM C-133/97.

[17] A. M. Segadães, Refratários, Universidade de Aveiro,
Portugal (1997).

[18] C. S. Prasad, K. N. Maiti, Interceram. 47, 4 (1998) 221227.

[19] J. M. F. Navarro, El Vidrio, CSIC, Madrid (1991) 99.

[20] W. E. Lee, Y. Iqbal, J. Eur. Ceram. Soc. 21, 14 (2001) 2583-2586.

[21] R. A. Eppler, J. Am. Ceram. Soc. 46, 2 (1963), 100.

[22] J. F. Shairer, J. Am. Cer. Soc. 40, 7 (1957) 215-235.

[23] R. W. Davidge, Mechanical behaviour of ceramics, Cambridge University Press, Cambridge, Inglaterra (1979).

[24] S. R. Bragança, C. P. Bergmann, Cerâmica 50, 314 (2004) 145-155.

[25] W. M. Carty, Ceram. Eng. Sci. Proc. 23, 2 (2002) 7994.

[26] K. H. Schüller, Porcelain, Ceramics Monographs - A Handbook of Ceramics, Verlag Schmidt GmbH Freiburg i. Brg. (1979).

[27] C. W. Sinton, Raw materials for glass and ceramics, John Wiley \& Sons (2006).

(Rec. 15/01/2009, Rev. 24/04/2009, 03/09/2009, Ac. 23/10/2009) 